\title{
A New Aneurysm Occlusion Classification after the Impact of Flow Modification
}

\author{
H.S. Cekirge and I. Saatci
}

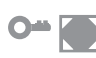

\begin{abstract}
SUMMARY: A new classification is proposed for cerebral aneurysms treated with any endovascular technique, for example, coiling with or without adjunctive devices, flow diversion, intrasaccular flow modifiers, or any combination of the above. Raymond-Roy Occlusion Classification is expanded with novel subgroups such as class 1 represents complete occlusion and is subdivided if a branch is integrated to, or originated from, the aneurysm sac; class 2 represents neck filling; class 3 represents incomplete occlusion with aneurysm filling as in the previous classification; and class 4 describes the immediate postoperative status after extra- or intrasaccular flow modification treatment. A new concept, "stable remodeling," is included as class 5, which represents filling in the neck region that stays unchanged or reduced, as shown with at least 2 consecutive control angiographies, at least 6 months apart, for not $<1$ year, or the remodeled appearance of a dilated and/or tortuous vessel in continuation with the parent artery without sac filling.
\end{abstract}

ABBREVIATION: $F M=$ flow modifier

A lthough endovascular cerebral aneurysm treatment has already been established, ${ }^{1,2}$ there is still controversy in regard to the possibility of not always providing complete occlusion or showing recanalization. However, it has also been shown that only a small group of incomplete occlusions or aneurysm remnants have clinical relevance. ${ }^{3,4}$ However, the Cerebral Aneurysm Rerupture After Treatment study ${ }^{5}$ reported that the degree of aneurysm occlusion after treatment was strongly associated with risk of rerupture. Aneurysm re-treatment may or may not carry a higher risk than the stable incomplete occlusion or recanalization. ${ }^{6,7}$ Unfortunately, the relevant information mostly originates from coiled aneurysms and, therefore, may not be generalized to the entire population of cerebral aneurysms, particularly those aneurysms treated with new devices that modify flow from inside or outside of the aneurysm sac.

Flow modifiers (FMs) (dedicated extrasaccular flow diverters, multiple stent-in-stent applications, and intrasaccular flow disrupters) have been introduced as a new concept for

Received March 9, 2015; accepted after revision June 8.

From the Department of Radiology (H.S.C), Bayindir Hospital, Ankara, Turkey; and Department of Radiology (I.S.), Yüksek Ihtisas University, Koru Hospital, Ankara, Turkey.

Please address correspondence to Isil Saatci, MD, Incek Bulvari Havuzlubag Evleri No: 11, Incek, Golbasi, Ankara, 06830, Turkey; e-mail: isaatci@gmail.com

- Indicates open access to non-subscribers at www.ajnr.org

7 Indicates article with supplemental on-line photo.

http://dx.doi.org/10.3174/ajnr.A4489 treatment of cerebral aneurysms; FMs cause, over time, curative reconstruction of the aneurysm neck. The reconstruction after extrasaccular FMs (ie, flow diverters) starts immediately after the construct is in place and then evolves over a period of weeks to months. ${ }^{8}$ Intrasaccular FMs (ie, flow disrupters) may result in instantaneous occlusion after placement or may require some time for final effect. ${ }^{9}$ The delay in aneurysm occlusion with FMs occurs consistently if the flow through the sac continues due to flow demand through a branch coming off or integrated into the sac. Hence, in most cases, the initial result immediately after treatment does not represent the ultimate goal, and reconstruction proceeds after surgery over time..$^{8,9}$ Overall, it is evident that evolution of aneurysm management necessitates development of unified terminology to describe both initial and delayed procedural efficacies, regardless of treatment technique.

In the literature, there have been several classifications published to describe the appearance of aneurysm and/or remnant filling. The Raymond-Roy Occlusion Classification, also known as the Montreal scale ${ }^{10}$ has been the most widely used, and it classifies the results after aneurysm coiling, which can be applied immediately after the treatment as well as during the followup. ${ }^{10,11}$ In the literature, there exist some articles about the implications on future management of aneurysm and/or neck remnants that state class 3 aneurysm remnants, according to Raymond-Roy Occlusion Classification, are more likely to be retreated than class 2 neck remnants, which are most often followed up. $^{12,13}$

AJNR Am J Neuroradiol 37:19-24 Jan 2016 www.ajnr.org 
Class 1: Complete occlusion of the aneurysm sac. When there is a branch integrated with the aneurysm sac, ie, coming off the aneurysm, at any point of the sac, further analysis is carried out with subgroups

1A: Complete occlusion with the full patency of the integrated branch

1B: Complete occlusion with the branch reduced in caliber

1C: Complete occlusion with no antegrade filling of the branch

Class 2: Neck filling

Class 3: Incomplete occlusion with aneurysm filling

Class 4: Aneurysm filling. This class is reserved for an immediate postoperative result based on end-of-treatment DSA; after extraand/or intrasaccular flow modification treatment

4A: With contrast stagnation-contrast stagnation is referred to when there happens to be any change in the duration of the contrast stay within the aneurysm sac after treatment

4B: Without contrast stagnation

Class 5: Stable remodeling with flow modification. Filling in the neck region, which stays unchanged or reduced; to be included in this group, there have to be at least 2 consecutive control angiographies, by definition, at least 6 months apart, and expanding for a period of not $<1$ year; exceptionally, 1 control angiography could be sufficient for definition of class 5 , only in selected cases of contrast filling the branch coming off the sac, with an appearance of a different vessel course than the original, eg, tortuous or dilated, given that it is in continuation with the parent artery with no sac filling

The introduction of extrasaccular flow diverters created a need for different classifications, not only to describe the initial results but also to anticipate the outcome, including the risk of infrequent but severe complications of postoperative rupture. ${ }^{14-16}$ However, these classifications are exclusively for the extrasaccular FMs, and, yet, none has gained common acceptance.

Subsequently, with the use of intrasaccular FMs, the control angiographic findings become even more controversial. Lubicz et $\mathrm{al}^{17}$ described 4 patterns in the follow-up of intrasaccular FM treatment, namely, complete occlusion, filling of the proximal recess of the device, neck remnant, and aneurysm remnant. Based on their follow-up experience, the investigators suggested a different definition, that is, "adequate occlusion," which includes the first 3 patterns.

So far in the literature, none of the classifications address the entire spectrum of current endovascular aneurysm treatment, irrespective to treatment technique. To solve this problem of ambiguity and to exclude the need for the use of different classifications for different modalities, we propose a new classification system, by expanding on the widely used Raymond-Roy Occlusion Classification scale, that describes results with current and evolving treatment techniques.

\section{MATERIALS AND METHODS}

The proposed classification is presented in the Table, and the schematic drawing (Fig 1) highlights the newly added class $1 \mathrm{~A}, \mathrm{~B}$, and $\mathrm{C}$ as well as class 5 in different case settings. Class 1 calls for complete occlusion of an aneurysm when a branch is not directly involved, and the subgroups of class $1-\mathrm{A}, \mathrm{B}, \mathrm{C}$ - are to be used when a branch is originating directly from a sidewall aneurysm (Figs 2 and 3) or filling from a bifurcation aneurysm (Fig 4). To assign class 5 (Figs $4 B$ and 5-7; On-line Figs 1 and 2), at least 2 angiographic controls, at least 6 months apart, and expanding for a period of not $<1$ year are required to demonstrate the stability. DSA is the criterion standard at the moment, although CTA may serve the purpose for the aneurysms treated with FMs. However, with the evolving technology, noninvasive angiographic imaging may replace this in the future. The remodeling concept ${ }^{18}$ was first

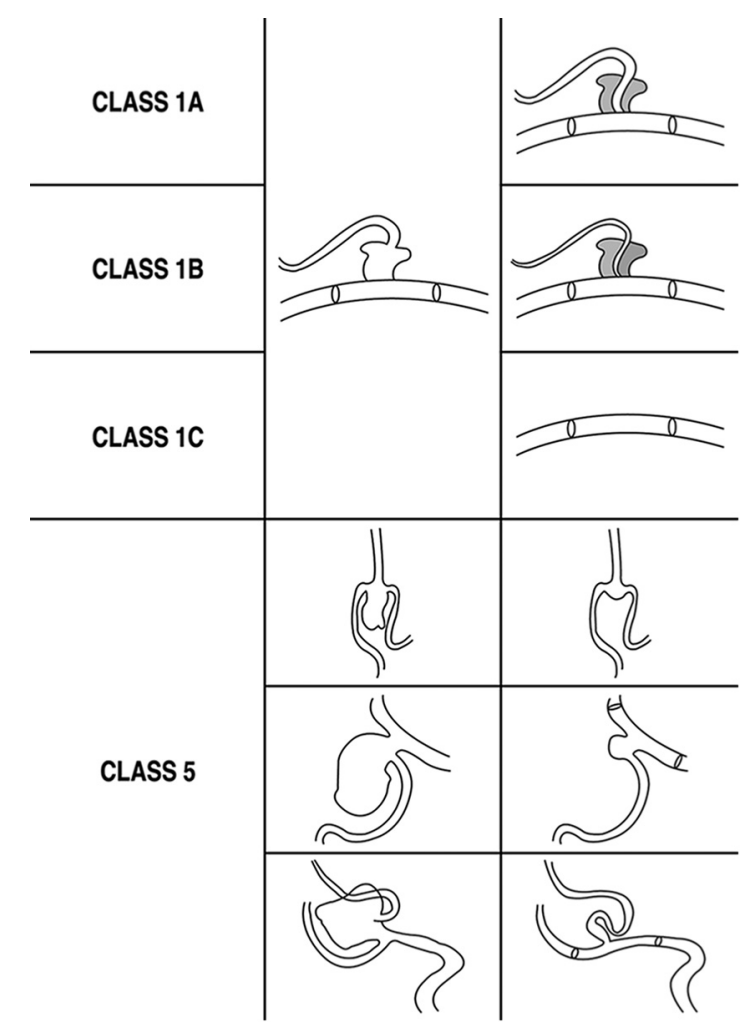

FIG 1. Schematic drawing of class 1 subgroups and class 5 in different case settings. The last column shows the control angiographic appearance. The first example of class 5 represents the control result after intrasaccular FM placement, given that the control appearance remains unchanged, as required. The second and third examples of class 5 represent the remodeling after extrasaccular flow diverter treatment.

defined in a more restricted concept that referred to 1 as "infundibulum like" enlargement of the branch coming off the aneurysm sac after the shrinkage of the aneurysm after flow diverter treatment (Fig 5) and 2, as a tortuous course of the branch (which is coming off the aneurysm sac) at its proximal segment after flow diverter treatment of the sac and the sac not filling (Figs 4 and 7). ${ }^{19}$ These 2 situations, in which the branch that originates from 

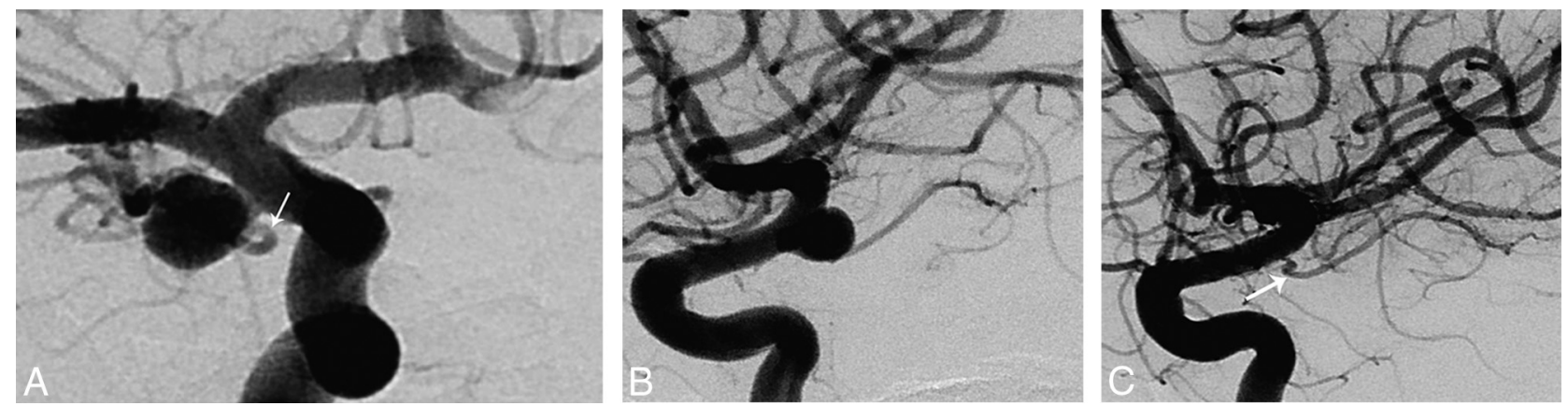

FIG 2. Class $1 A$. $A$ and $B$, Preoperative images show the ICA aneurysm in which the anterior choroidal artery (arrow) is originating from the aneurysm at the neck. C, Six-month control angiography after single Pipeline device (Covidien, Irvine, California) placement demonstrates total occlusion of the aneurysm with the anterior choroidal artery preserved (arrow). Reprinted from Saatci et al. ${ }^{18}$
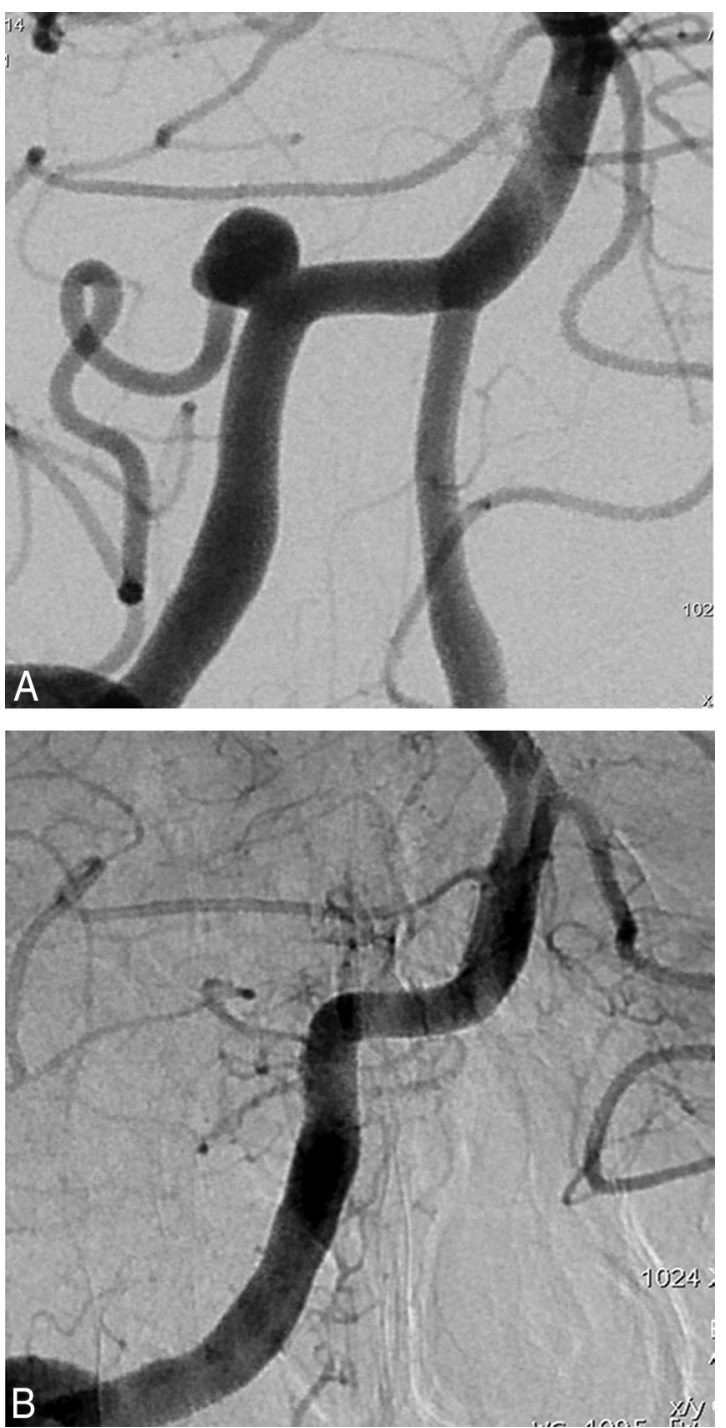

FIG 3. Class 1C. $A$, Preoperative angiography shows right vertebral artery aneurysm with the posterior inferior cerebellar artery originating from the sac. $B$, Single Pipeline device was placed, and a 6-month control angiography demonstrates complete occlusion of the aneurysm sac, along with the posterior inferior cerebellar artery. The patient was asymptomatic.

the aneurysm sac is in continuation with the parent artery with no filling of the sac any more, are the only exceptions for which we do not require a second angiography to grade as class 5 occlusion
(On-line Fig 1 for class 5 after intrasaccular FM). In the other situations, remodeling is called for after confirmation of the stability (as described above) when 3, the bifurcation appears enlarged after the intrasaccular FM obliterates the sac, which stays stable in the controls (Fig 6), and 4, when there is an unchanged focal bulging at the neck region (On-line Fig 2). Therefore, in such cases, the first control result would be classified as class 2 (neck remnant) by definition; then, after confirmation of stability, it can be changed to class 5 (Fig 6 and On-line Fig 2).

\section{DISCUSSION}

The healing process or so-called reconstruction of the vessel wall at the aneurysm neck after FM and/or flow diverter treatment is different from that after endosaccular coiling, ${ }^{18,20-22}$ and aneurysms may behave differently when treated with flow modification treatments versus endosaccular coiling. ${ }^{23,24}$ Therefore, the previous classifications, particularly Raymond-Roy Occlusion Classification, described for coiled aneurysms could not address the results of flow modification treatments. Several new classifications $^{14,17}$ have been introduced. In these previous classifications for extrasaccular flow diverter treatment, flow stagnation is defined as a determining feature. ${ }^{14-16}$ However, the flow stagnation does not necessarily have a direct implication regarding the future or final treatment result. That is, flow stagnation within the aneurysm may or may not result in total occlusion of the aneurysm sac. On the contrary, an aneurysm that shows no or little, if any, postoperative contrast stagnation may end up in complete occlusion in the follow-up. Yet, the presumed importance of the contrast stagnation is whether or not it has any predictive value in regard to postoperative rupture of the index (treated) aneurysm. This is a controversial issue, with no proven data to date. Our classification system does not emphasize the degree of contrast filling (eg, the pattern, timing) immediately after the FM treatment, not only for these reasons but also because it may be relatively subjective or may vary in regard to technical parameters, such as contrast injection power, acquisition parameters, and so forth. Contrast stagnation is referred to in the immediate postoperative DSA findings (class 4) after FM treatment to differentiate that grade from the aneurysm filling after aneurysm packing (class 3 ).

In some grading scales previously described exclusively for use after flow diverter treatment, ${ }^{15,16}$ parent artery size is taken into 

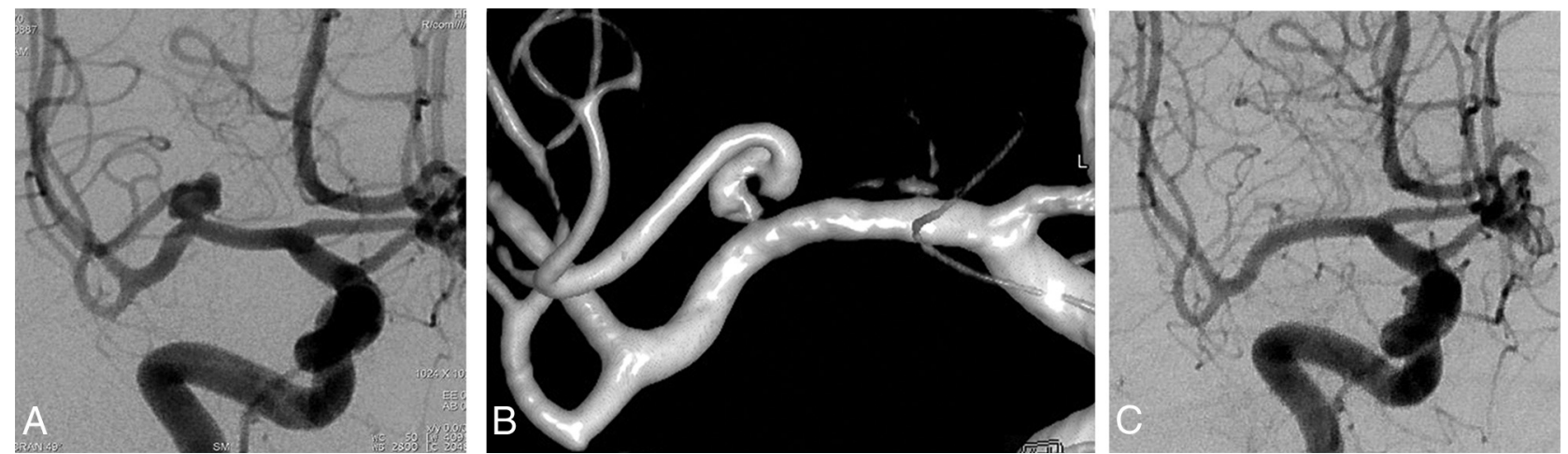

FIG 4. Class 5 evolving into class $1 B$ eventually. A, Preoperative angiography shows right MCA aneurysm with a branch coming off from the sac. $B, A$ 3D image from a 6-month control angiography after treatment with single Pipeline device shows remodeling of the flow with a tortuous appearance of the branch proximally at its direct continuation with the parent artery, and no sac filling. This appearance is referred to as class 5. C, An 18-month control angiography shows complete occlusion of the aneurysm with the originating branch in reduced caliber, that is, class 1B. Reprinted from Yavuz et al. ${ }^{19}$
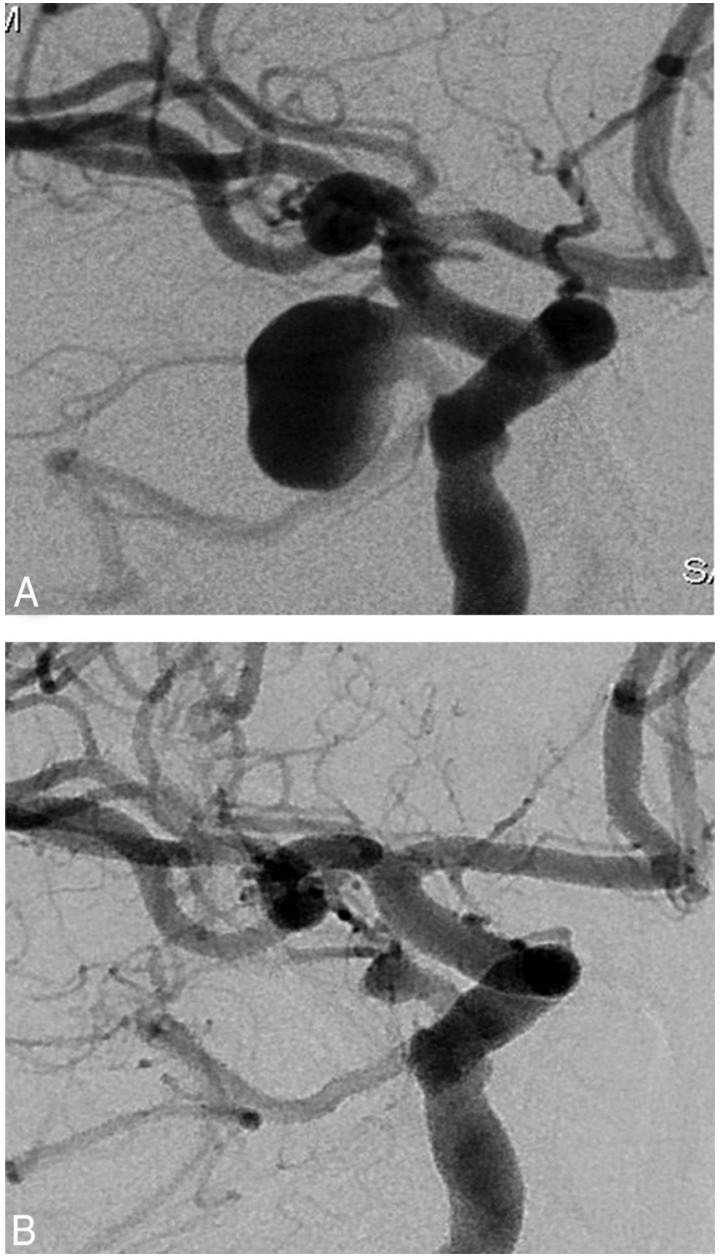

FIG 5. Class 5. A, Right internal carotid angiogram shows a posterior communicating artery aneurysm (the ipsilateral Pl is aplastic, not shown). B, A 2-year angiography after a single Pipeline device placement shows that the aneurysm sac is not filling and the origin of the posterior communicating artery is remodeled. Reprinted from Saatci et al..$^{18}$

consideration. Parent artery occlusion may occur, at least in some cases, related to the inefficiency of antiaggregating medication, but, the rate of in-stent stenosis is reported to be not any higher than that of conventional stents ${ }^{18,22}$ and in-stent stenosis is not a part of this classification.

The patency of the branch that originates from, or is integrated to, the aneurysm is assessed in this classification, which has not been included in previous classifications. The flow demand through the relevant branch is important in its patency after the treatment. ${ }^{18-20}$ Although the aneurysm is getting occluded, the branch originating from the aneurysm may remain the same, reduce in caliber, or may not be filling antegrade. This classification can apply to the results of flow diverter treatment not only in sidewall aneurysms but also in bifurcation aneurysms ${ }^{19}$; the series of exclusive MCA bifurcation aneurysms treated with flow diverter placement demonstrated $84 \%$ of class 1 occlusions with a variety of occlusion patterns, including branch occlusion in $12 \%$. Another $8 \%$ showed class 5 occlusion. In addition, transition between classes is also possible (Fig 4) in the group of aneurysms with integrated branches, whether located at the side wall or the bifurcation.

This classification is also well grounded for the intrasaccular FM treatments in that it takes not only the involving branches into consideration but also the interval change in regard to stability. With these features, this classification is differentiated from the classification for intrasaccular FMs previously described. ${ }^{17}$

Another advantage of this proposed classification is that it can be applied by single angiographic images, in several planes, and does not necessitate seeing the entire series of the angiographic run to evaluate the flow pattern within the aneurysm. Therefore, objective findings on the angiographic image are enough for classification, with no further subjective interpretation. However, rotational angiography may be a requisite, particularly in the definition of class 5 in some cases.

\section{CONCLUSIONS}

With preventing rupture as the ultimate goal of cerebral aneurysm treatment, if the treatment serves this purpose and the aneurysm is secured, then the treatment can be called "successful" and the angiographic appearance of the vascular reconstruction can be considered irrelevant. Long-term stability of remodeling is to be determined and not free of concern until that time. How- 

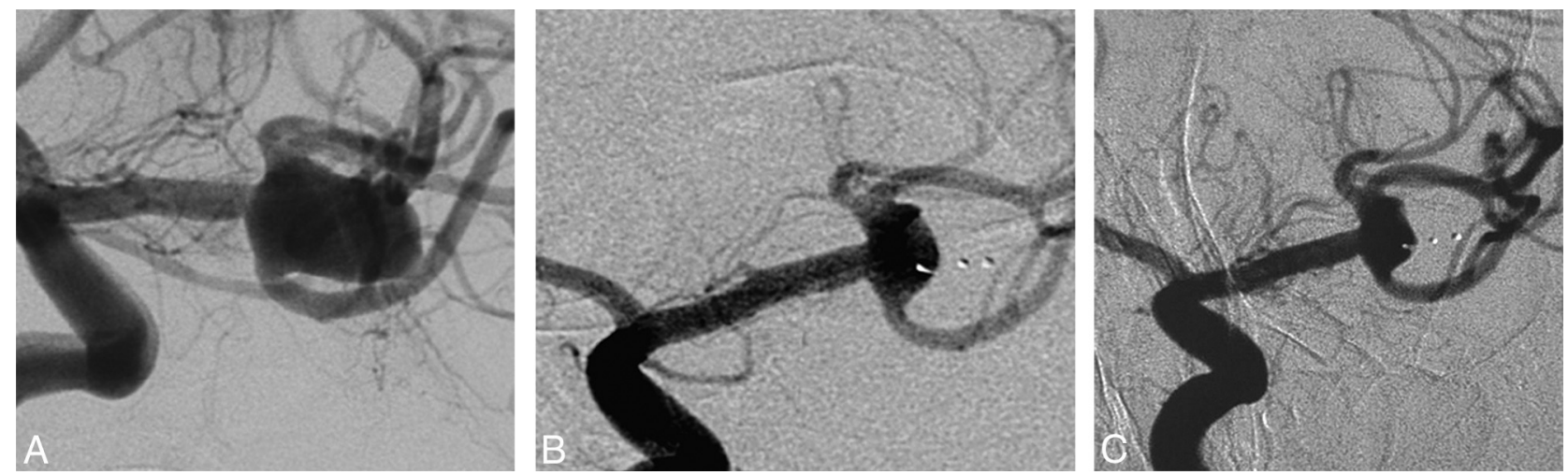

FIG 6. Class 5. A, Preoperative angiography shows a large left MCA aneurysm at the trifurcation, with the branches incorporated in the sac. $B$, Six months after the treatment with a WEB device (Sequent Medical, Aliso Viejo, California), control angiography shows neck filling at the trifurcation, with the branches patent, and this result is classified as class 2. C, An 18-month control angiography shows an unchanged appearance of the MCA trifurcation, and this result is classified as class 5, with the apparently "stable" remodeling.
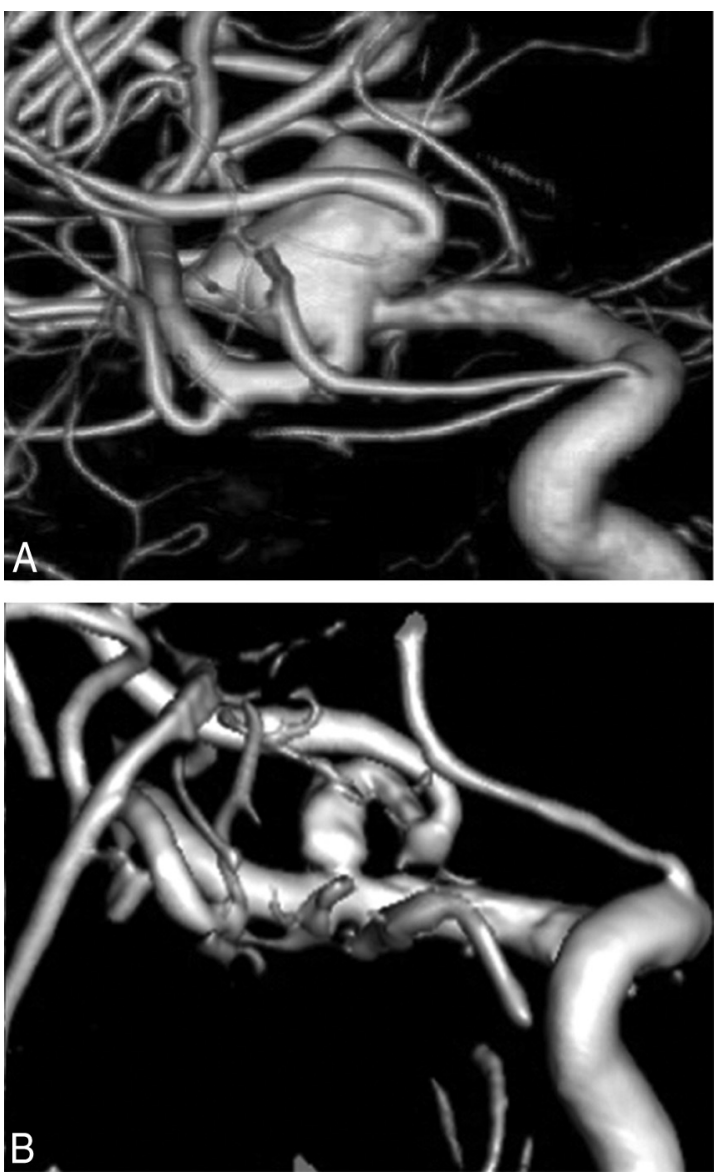

FIG 7. Class 5. A, Preoperative angiography shows a large, irregular shaped, right MCA bifurcation aneurysm with both bifurcation branches coming off the sac. A Pipeline device was placed, extending from the inferior trunk to the MI in addition to a WEB device within the sac. B, A 6-month control angiography shows a patent inferior trunk, a tortuous origin of the superior trunk, no sac filling; this result is referred to as class 5 .

ever, in complex aneurysms where "perfect" anatomic results may not be possible or at least have increased risks, then, "remodeling" may be acceptable, given that it is stable. This classification not only addresses the new concept of remodeling that emerged after the use of extra- and intrasaccular flow modifications but also covers the entire spectrum of result possibilities with any current technique.

We acknowledge that this classification should be validated in regard to the interobserver agreement to test its reproducibility. In addition, we also plan to extract a random sample of credible size among our entire aneurysm population to review the stability in long-term follow-up (eg, 5 years) to investigate the outcome of "designated" classes. This classification may then be ready to establish a clinical algorithm for follow-up, including the risk of bleeding after endovascular treatment.

Disclosures: H. Saruhan Cekirge-UNRELATED: Consultancy: Covidien/Medtronic, MicroVention, Sequent. Isil Saatci-UNRELATED: Consultancy: Covidien, Medtronic.

\section{REFERENCES}

1. Molyneux A, Kerr R, Stratton I, et al; International Subarachnoid Aneurysm Trial (ISAT) Collaborative Group. International Subarachnoid Aneurysm Trial (ISAT) of neurosurgical clipping versus endovascular coiling in 2143 patients with ruptured intracranial aneurysms: a randomised trial. Lancet 2002;360:1267-74 CrossRef Medline

2. McDougall CG, Spetzler RF, Zabramski JM, et al. The Barrow Ruptured Aneurysm Trial. J Neurosurg 2012;116:135-44 CrossRef Medline

3. Campi A, Ramzi N, Molyneux AJ, et al. Retreatment of ruptured cerebral aneurysms in patients randomized by coiling or clipping in the International Subarachnoid Aneurysm Trial (ISAT). Stroke 2007;38:1538-44 CrossRef Medline

4. Molyneux AJ, Birks J, Clarke A, et al. The durability of endovascular coiling versus neurosurgical clipping of ruptured cerebral aneurysms: 18 year follow-up of the UK cohort of the International Subarachnoid Aneurysm Trial (ISAT). Lancet 2015;385:691-97 CrossRef Medline

5. Johnston SC, Dowd CF, Higashida RT, et al; CARAT Investigators. Predictors of rehemorrhage after treatment of ruptured intracranial aneurysms: the Cerebral Aneurysm Rerupture After Treatment (CARAT) study. Stroke 2008;39:120-25 CrossRef Medline

6. Molyneux AJ, Kerr RS, Birks J, et al; ISAT Collaborators. Risk of recurrent subarachnoid haemorrhage, death, or dependence and standardised mortality ratios after clipping or coiling of an intracranial aneurysm in the International Subarachnoid Aneurysm Trial (ISAT): long-term follow-up. Lancet Neurol 2009;8:427-33 CrossRef Medline

7. Crobeddu E, Lanzino G, Kallmes DF, et al. Review of 2 decades of aneurysm-recurrence literature, part 2: managing recurrence after 
endovascular coiling. AJNR Am J Neuroradiol 2013;34:481-85 CrossRef Medline

8. Fiorella D, Lylyk P, Szikora I, et al. Curative cerebrovascular reconstruction with the Pipeline embolization device: the emergence of definitive endovascular therapy for intracranial aneurysms. $\mathrm{J} \mathrm{Neu}$ rointerv Surg 2009;1:56-65 CrossRef Medline

9. Ding YH, Lewis DA, Kadirvel R, et al. The Woven EndoBridge: a new aneurysm occlusion device. AJNR Am J Neuroradiol 2011;32:607-11 CrossRef Medline

10. Roy D, Milot G, Raymond J. Endovascular treatment of unruptured aneurysms. Stroke 2001;32:1998-2004 CrossRef Medline

11. Raymond J, Guilbert F, Weill A, et al. Long-term angiographic recurrences after selective endovascular treatment of aneurysms with detachable coils. Stroke 2003;34:1398-403 CrossRef Medline

12. Mascitelli JR, Moyle H, Oermann EK, et al. An update to the Raymond-Roy Occlusion Classification of intracranial aneurysms treated with coil embolization. J Neurointerv Surg 2015;7:496-502 CrossRef Medline

13. Mascitelli JR, Oermann EK, De Leacy RA, et al. Angiographic outcome of intracranial aneurysms with neck remnant following coil embolization. J Neurointerv Surg 2015;7:484-89 CrossRef Medline

14. O'Kelly CJ, Krings T, Fiorella D, et al. A novel grading scale for the angiographic assessment of intracranial aneurysms treated using flow diverting stents. Interv Neuroradiol 2010;16:133-37 CrossRef Medline

15. Kamran M, Yarnold J, Grunwald IQ, et al. Assessment of angiographic outcomes after flow diversion treatment of intracranial aneurysms: a new grading schema. Neuroradiology 2011;53:501-08 CrossRef Medline

16. Grunwald IQ, Kamran M, Corkill RA, et al. Simple measurement of aneurysm residual after treatment: the SMART scale for evaluation of intracranial aneurysms treated with flow diverters. Acta Neurochir (Wien) 2012;154:21-26; discussion 26 CrossRef Medline

17. Lubicz B, Klisch J, Gauvrit JY, et al. WEB-DL endovascular treatment of wide-neck bifurcation aneurysms: short- and midterm results in a European study. AJNR Am J Neuroradiol 2014;35:432-38 CrossRef Medline

18. Saatci I, Yavuz K, Ozer C, et al. Treatment of intracranial aneurysms using the Pipeline flow-diverter embolization device: a single-center experience with long-term follow-up results. AJNR Am J Neuroradiol 2012;33:1436-46 CrossRef Medline

19. Yavuz K, Geyik S, Saatci I, et al. Endovascular treatment of middle cerebral artery aneurysms with flow modification with the use of the Pipeline embolization device. AJNR Am J Neuroradiol 2014;35: 529-35 CrossRef Medline

20. Dai D, Ding YH, Kadirvel R, et al. Patency of branches after coverage with multiple telescoping flow-diverter devices: an in vivo study in rabbits. AJNR Am J Neuroradiol 2012;33:171-74 CrossRef Medline

21. Pierot L, Liebig T, Sychra V, et al. Intrasaccular flow-disruption treatment of intracranial aneurysms: preliminary results of a multicenter clinical study. AJNR Am J Neuroradiol 2012;33:1232-38 CrossRef Medline

22. Becske T, Kallmes DF, Saatci I, et al. Pipeline for uncoilable or failed aneurysms: results from a multicenter clinical trial. Radiology 2013; 267:858-68 CrossRef Medline

23. Kadirvel R, Ding YH, Dai D, et al. Cellular mechanisms of aneurysm occlusion after treatment with a flow diverter. Radiology 2014;270: 394-99 CrossRef Medline

24. Dai D, Ding YH, Rezek I, et al. Characterizing patterns of endothelialization following coil embolization: a whole-mount, dual immunostaining approach. J Neurointerv Surg 2015 Feb 2. [Epub ahead of print] CrossRef Medline 